GU J Sci, Part C, 6(4): 741-752 (2018)

Gazi Üniversitesi
Fen Bilimleri Dergisi
PART C: TASARIM VE TEKNOLOJI
http://dergipark.gov.tr/gujsc

\title{
Bilyalı Dövme Parametrelerinin AA7075 T6 Alüminyum Alaşımının Yüzey Altı Özelliklerine Etkileri
}

\author{
Egemen AVCU ${ }^{1, *}$

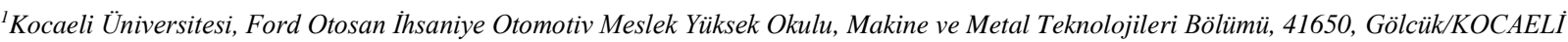

\begin{abstract}
$\ddot{O} \mathbf{z}$
Makale Bilgisi

Başvuru: 20/02/2018

Düzeltme: 30/06/2018

Kabul: 12/11/2018

Anahtar Kelimeler

AA7075 T6 alașımı

Bilyalı dövme

Bilya boyutu

Püskürtme basincl

Mikroyap

Sertlik

Bilyalı dövme işlemi özellikle otomotiv ve havacılık endüstrilerinde değişken yüklemeler altında çalı̧an makine elemanlarının yorulma ömürlerinin geliştirilmesi için yaygın olarak uygulanan önemli bir mekanik yüzey işleme yöntemidir. Yorulma ömrünün geliştirilmesi; bilyalı dövme ile malzeme yüzey altı mikroyapısı ve mekanik özelliklerinin iyileştirilerek çatlak oluşumunun engellenmesi ve oluşan çatlakların ilerleme hızlarının yavaşlatılması ile sağlanmaktadır. Bu çalışmada farklı bilyalı dövme parametreleri altında dövülen AA7075 T6 alüminyum alaşımının yüzey altı mikroyapısında ve mekanik özelliklerinde meydana gelen değişimlerin incelenmesi amaçlanmıştır. Bilya boyutu ve bilya püskürtme basıncı parametrelerinin yüzey altı sertlik değerlerine ve yüzey altı mikroyapısına etkileri derinliğe bağlı olarak incelenmiştir. Bilyalı dövme deneyleri özel olarak tasarlanan bilyalı dövme test sisteminde $0,1-0,3 \mathrm{~mm}$ ve $0,4-0,9 \mathrm{~mm}$ çaplarında paslanmaz çelik bilyalar ile 2 ve 4 bar püskürtme basınçları altında gerçekleştirilmiştir. Püskürtme basıncı ve bilya boyutunun artışı ile yüzey altı sertlik değerleri belirgin bir şekilde iyileşmiş ve sertlik artışı gözlenen bölgenin derinliği artmıştır. Püskürtme basıncının artışı ile her iki bilya boyutunda da mikroyapısal değişime uğrayan bölgenin derinliği artış göstermiştir. Püskürtme basıncı ve bilya boyutu artışı nedeniyle meydana gelen aşırı plastik deformasyon nedeniyle yüzeyde derin ve geniş çukurcukların ve yüzeysel mikro çatlakların oluşumu belirlenmiştir.
\end{abstract}

Keywords

AA7075 T6 alloy

Shot peening

Shot size

Peening pressure

Microstructure

Hardness

\section{The Effects of Shot Peening parameters on the subsurface properties of AA7075 T6 aluminum alloy}

\begin{abstract}
Shot peening (SP) is an important mechanical surface treatment widely used to improve the fatigue life of mechanical components operating under dynamic loads which have been specifically used in automotive and aerospace industries. The enhancement of the fatigue life is achieved by preventing the crack formation and slowing crack propagation by improving the mechanical properties and the microstructure of subsurface via SP. In this study, it is aimed to investigate the variation of the subsurface microstructure and the subsurface mechanical properties of AA7075 T6 aluminum alloy shot-peened under different parameters. The subsurface hardness and microstructural variations were investigated in relation to depth depending on the shot size and the peening pressure. SP was conducted under specially designed SP system by stainless steel shots of 0.1-0.3 mm and 0.4-0.9 mm diameters under 2 and 4 bar peening pressures. Subsurface hardness values improved significantly by increasing pressure and shot size, and the depth of the hardness increased regions was increased. The depth of the microstructural region affected by SP also increased for both shot sizes. The formation of deep and large pits and surface microcracks were determined on the surface due to the excessive plastic deformation that occurs with increases in pressure and shot size.
\end{abstract}

\section{GİRIŞ (INTRODUCTION)}

Bilyalı dövme, metallerin yüzey ve yüzey altı özelliklerinin geliştirilmesi amacıyla yaygın olarak kullanılan mekanik bir yüzey işleme yöntemidir [1-5]. Bilyalı dövme yönteminde yüksek hızlarda tekrarlı bir şekilde malzeme yüzeyine çarpan bilyalar malzemenin yüzey ve yüzey altı özelliklerinde önemli pozitif değişimler meydana getirmektedir [2, 4, 6]. Bilyalı dövme ile; i) meydana gelen plastik deformasyon [4, 7] ve bölgesel mikro gerinmeler [2, 8-13] nedeniyle kalıntı basma gerilmesi oluşumu, ii) yüzeyde ve yüzey altında sertlik 
artış1 [5], iii) yüzey altı mikroyapısında dislokasyon artışı ve tane yapısının küçülmesi nedeniyle pekleşme [3-5, 13] gözlenmektedir. Yüzey ve yüzey altında meydana gelen bu olumlu gelişmeler sayesinde bilyalı dövme ile farklı endüstrilerde kullanılan çok sayıda yapısal malzemenin yorulma dayanımı ve ömrü geliştirilmektedir [2, 4, 6, 8-10,14]. Özetlenen bu yüzey ve yüzey altı özellikler ile malzemenin yorulma davranışlarını etkileyen çok sayıda bilyalı dövme işlem parametresi bulunmaktadır [14-18]. Bu parametreler bilya özellikleri (bilya türü, boyutu, sertliği, vb.) $[1,15,19]$ ve operasyon parametreleri (bilya çarpma hızı, Almen şiddeti, örtme oranı, püskürtme basıncı, dövme süresi, vb.) [3, 15, 16, 19-22] olarak sınıflandırılabilir. Bilyalı dövmenin düşük maliyetli ve kolay uygulanabilir olması ile değişken yüklemeler altında çalışan mühendislik malzemelerinin yorulma ömrünün geliştirilmesi gerekliliği bilyalı dövme işlemini farklı endüstriyel uygulamalar için vazgeçilmez bir yüzey işleme yöntemi konumuna getirmektedir $[1,2,5,8-11,14,22,23]$.

Alüminyum alaşımları son yıllarda özellikle yakıt tüketiminin azaltılması gereken otomotiv ve havacılık endüstrilerinde yoğun talep görmektedir [24]. Yüksek spesifik dayanım özellikleri, yüksek korozyon dayanımı, kolay işlenebilirliği, yüksek tokluk ve yorulma dayanımı sayesinde alüminyum alaşımları otomotiv, denizcilik, uzay ve havacılık endüstrilerinde yapısal elemanlarının üretiminde yaygın olarak kullanılmaktadır [25-34]. 7xxx serisi alüminyum alaşımları, özellikle AA7075 alüminyum alaşımı, uygulanan 1sıl işlemler ile birlikte yüksek akma (yaklaşı $490 \mathrm{MPa}$ ) ve çekme dayanımı (yaklaşık (570 MPa) özellikleri göstermektedir [28]. Literatürde alüminyum alaşımlarının mekanik özelliklerinin daha fazla iyileştirilmesi ve özelikle yorulma ömürlerinin arttırılması için bilyalı dövme yaygın olarak uygulanmıştır [12, 35-38].

Literatürde gerçekleştirilen çalışmalarda AA7075 alüminyum alaşımlarının bilyalı dövme ile yukarıda özetlenen yüzey ve yüzey altı özellikleri geliştirilerek yorulma ömürleri ve dayanımları geliştirilebildiği belirtilmiştir [1, 35, 39]. Trsko ve arkadaşları [14] AW7075 alüminyum alaşımının yorulma ömrünün optimum parametreler altında uygulanan bilyalı dövme işlemi ile geliştirildiğini, ancak bilyalı dövme şiddetinin aşırı olması durumunda yorulma dayanımının azaldığını belirtmiş̧lerdir. Nam ve arkadaşları [37] havacılıkta kullanılan Al alaşımının (2124-T851) yüzey altı özelliklerini bilyalı dövme ile geliştirmeyi amaçlamışlardır. Nozul mesafesi, bilya püskürtme basıncı, bilya çarpma açısı ve bilyalı dövme süresi gibi önemli işlem parametrelerinin alüminyum alaşımının mikro sertliğine ve kalıntı basma gerilmesine olan etkilerini araştırmışlardır. Araştırma sonucunda bu parametrelerin mikro sertliği ve kalıntı basma gerilmesini önemli ölçüde etkilediğini belirlemişlerdir [37]. Bilya püskürtme basıncı, çarpma açısı ve dövme süresinin artışı ile mikro sertliğin ve kalıntı basma gerilmesi değerinin arttığını raporlamışlardır [37]. Zupanc ve Grum [39] AA7075-T651 alaşımının yorulma performansına bilyalı dövme işleminin etkilerini incelemişlerdir. Gerçekleştirdikleri çalışmalar sonucunda bilyalı dövmenin AA7075 alaşımının mikro sertliğini, kalıntı gerilme değerini ve yüzey pürüzlülüğünü arttırdığ 1 görülmüş, bu değişimler sonucunda yorulma dayanımının iyileştiği belirlenmiştir [39]. Oguri [38] gerçekleştirdiği çalışmada küçük boyutlu ve partikül boyut dağılımı yakın olan seramik esaslı bilyalar ile yüksek çarpma hızlarında AA7075T6 alaşımına özel bir bilyalı dövme işlemi uygulamıştır. Bu çalışmalar sonucunda uyguladığı özel bilyalı dövme işleminin normal bilyalı dövme işlemine kıyas ile kalıntı basma gerilimi oluşumunu arttırdığ 1 ve bunun sonucunda yorulma ömrünü daha fazla geliştirdiğini belirlemiştir [38]. Son yıllarda literatürde 2124T851 [37] ve 5056 [36] gibi farklı alüminyum alaşımlarının mekanik özelliklerinin ve yorulma davranışlarının bilyalı dövme ile geliştirilmesi üzerine çok sayıda çalışma gerçekleştirilmiştir. Gerçekleştirilen çalışmaların büyük bir kısmında bilyalı dövme ve bilyalı dövme şiddeti gibi önemli işlem parametrelerinin alüminyum alaşımlarının yorulma ömrüne etkileri üzerine odaklanılmıştır. Ancak bilya püskürtme basıncı ve özellikle bilya boyutunun alüminyum alaşımlarının bilyalı dövülme işleminde yüzey altı mekanik özellikleri ve mikroyapısal değişimleri üzerine odaklanmış kapsamlı çalışmalar bulunmamaktadır. Bu çalışmanın en önemli amacı endüstriyel uygulamalarda öne çıkan ve bilyalı dövme işleminin yaygın olarak uygulandığı AA7075-T6 alüminyum alaşımının mekanik ve mikroyapısal özelliklerine bilya boyutunun ve bilya püskürtme basıncının etkilerinin irdelenmesidir. 


\section{MALZEME VE YÖNTEM (MATERIALS AND METHOD)}

\subsection{Malzeme (Materials)}

Çalışmada kullanılan AA7075 T6 alüminyum alaşımı $25 \mathrm{~mm}$ çapında çubuk malzeme olarak tedarik edilmiştir. Tedarik edilen alüminyum alaşımının kimyasal kompozisyonu ve önemli mekanik özellikleri Tablo 1' de verilmiştir. Çubuk malzemeden bilyalı dövme deneyleri için gereken numuneler hassas kesme cihazı (Microcut 151, Metkon Instruments Inc., TR) ile 10 mm kalınlığında kesilmiştir.

Tablo 1. AA7075 T6 alüminyum alaşımının kompozisyonu ve önemli mekanik özellikleri

\begin{tabular}{|l|l|l|l|l|l|l|}
\hline \multicolumn{7}{|l|}{ Kimyasal kompozisyon } \\
\hline Elementler & $\mathrm{Al}$ & $\mathrm{Zn}$ & $\mathrm{Mg}$ & $\mathrm{Cu}$ & $\mathrm{Fe}$ & $\mathrm{Si}$ \\
\hline Kütlece (\%) & $87,1-91,4$ & $5,1-6,1$ & $2,1-2,9$ & $1,2-2$ & En fazla 0,5 & En fazla 0,4 \\
\hline & Mekanik özellikler \\
& $\begin{array}{l}\text { Sertlik } \\
(\text { Vickers) }\end{array}$ & $\begin{array}{l}\text { Çekmede akma } \\
\text { dayanımı } \\
(\mathrm{MPa})\end{array}$ & $\begin{array}{l}\text { Çekme } \\
\text { dayanımı } \\
(\mathrm{MPa})\end{array}$ & $\begin{array}{l}\text { Kopmada } \\
\text { uzama } \\
(\%)\end{array}$ & $\begin{array}{l}\text { Elastisite } \\
\text { modülü } \\
(\mathrm{GPa})\end{array}$ \\
\hline & 175 & 503 & 570 & 11 & 71 \\
\hline
\end{tabular}

Bilyalı dövme işlemleri için 0,1-0,3 mm ve 0,4-0,9 mm partikül boyut aralıklarında ticari isimleri sırası ile Chronital S10 ve Chronital S60 olan paslanmaz çelik bilyalar kullanılmıştır. Paslanmaz çelik bilyaların taramalı elektron mikroskobu (SEM) fotoğrafları ve kimyasal kompozisyonları sırası ile Şekil 1 ve Tablo 2' de verilmiştir.

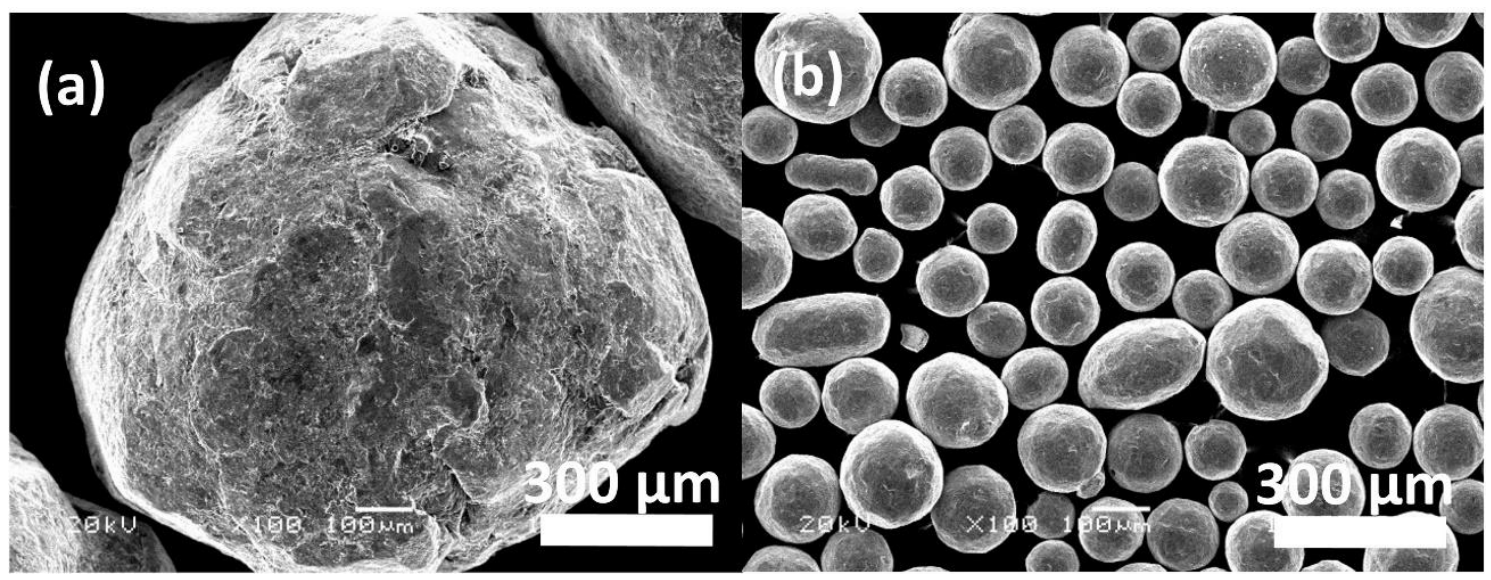

Şekil 1. Paslanmaz çelik bilyaların SEM fotoğrafları (a) 0,4-0,9 mm (S60), (b) 0,1-0,3 mm (S10)

Tablo 2. Paslanmaz çelik bilyaların kimyasal kompozisyonu

\begin{tabular}{|c|c|c|c|c|c|c|c|}
\hline Elementler & $\mathrm{C}$ & $\mathrm{Cr}$ & $\mathrm{Ni}$ & $\mathrm{Mn}$ & $\mathrm{Si}$ & $\mathrm{S}$ & $\mathrm{P}$ \\
\hline $\begin{array}{c}\text { Kütlece } \\
(\%)\end{array}$ & $0,10-0,13$ & $18,0-19,0$ & $8,0-10,0$ & $<2,0$ & $<3,0$ & $<0,03$ & $<0,04$ \\
\hline
\end{tabular}

\subsection{Yöntem (Method)}

10 mm kalınlığında kesilen AA7075 T6 alüminyum alaşımı parçalar bilyalı dövme uygulaması öncesinde metalografik olarak hazırlanmıştır. Kesilen parçalar zımpara ve parlatma cihazı (Forcipol 1V, Metkon Instruments Inc., TR) ile sırası ile 120, 320, 600 ve 100 meshlik zımparalar ile zımparalanmış ve sonrasında 6 ve 1 mikronluk elmas solüsyonlar ile parlatılmıştır. Parlatılan numunelerin yüzeyleri alkol ile temizlendikten sonra sıcak hava ile kurutulmuştur. 
Bilyalı dövme deneyleri özel olarak tasarlanan bilyalı dövme test sisteminde gerçekleştirilmiştir. Test sistemi kompresör, hava (nem) kurutucu, basınç regülatörü, bilyalı dövme kabini, bilya besleme haznesi, bilyalı dövme nozulu, numune tutucu ile bağlantı valfler ve basınçlı hava hortumu gibi pnömatik sistem ekipmanlarından oluşmaktadır (Şekil 2).

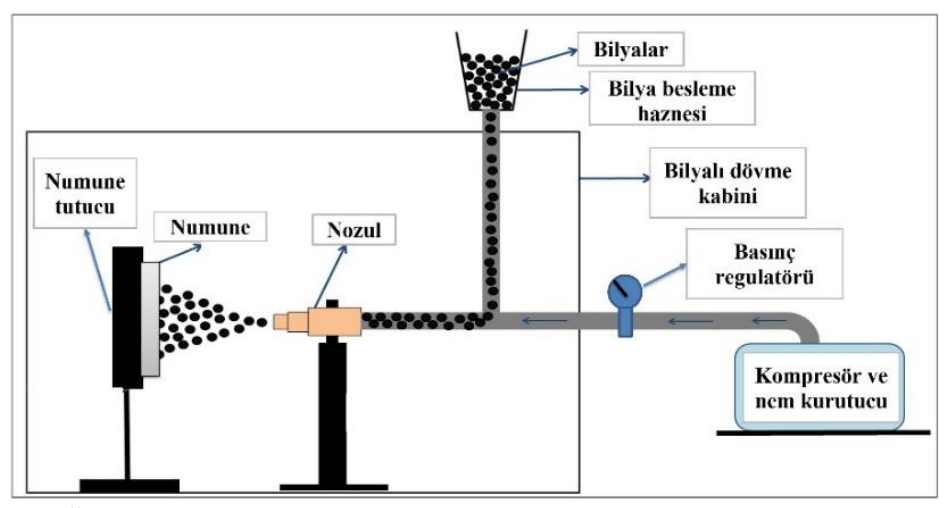

Şekil 2. Özel olarak tasarlanan bilyall dövme test sistemi ve bileşenleri

Özel olarak tasarlanan bilyalı dövme test sistemi; i) bilyalı dövme mesafesi, ii) bilya çarpma açısı, iii) bilya püskürtme basınc1, iv) bilyalı dövme süresi ve v) bilya boyutu gibi önemli bilyalı dövme işlem parametrelerinin istenildiği gibi ayarlanabilmesine olanak vermektedir. Bu çalışmada alüminyum numuneler iki farklı boyutta bilya kullanılarak iki farklı bilya püskürtme basıncı altında diğer tüm bilyalı dövme ișlem parametreleri sabit tutularak kontrollü olarak dövülmüștür. Uygulanan bilyalı dövme işlemi ve kullanılan parametreler Şekil 3' de şematik olarak verilmiştir. Çalışmada kullanılan bilyalı dövme parametreleri ve bu parametrelere bağlı olarak elde edilen bilyalı dövme şiddeti (Almen şiddeti) ve örtme oranı değerleri Tablo 3' de özetlenmiştir.

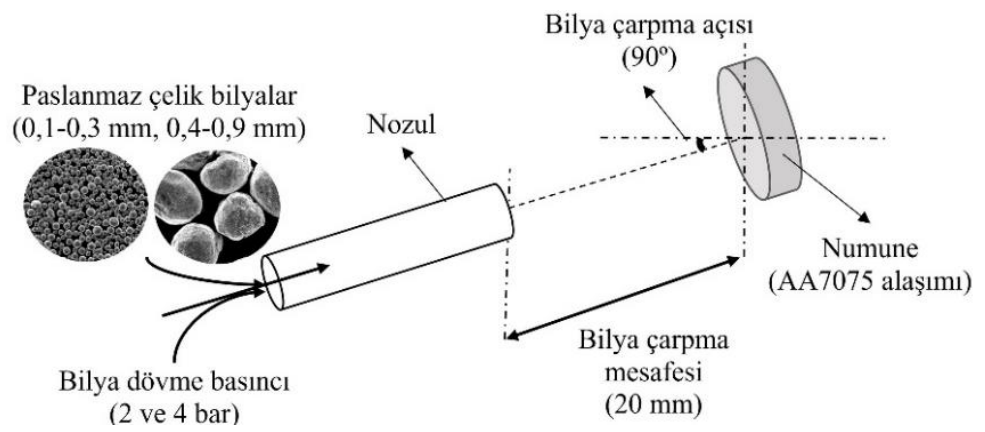

Şekil 3. Uygulanan bilyalı dövme işlemi ve işlem parametrelerinin şematik gösterimi

Tablo 3. Bilyalı dövme işlem parametreleri ve ölçülen Almen şiddetleri

\begin{tabular}{|c|c|c|c|c|c|c|}
\hline $\begin{array}{c}\text { Nozul çap1 } \\
(\mathrm{mm})\end{array}$ & $\begin{array}{c}\text { Nozul boyutu } \\
(\mathrm{mm})\end{array}$ & $\begin{array}{c}\text { Bilya boyutu } \\
(\mathrm{mm})\end{array}$ & $\begin{array}{c}\text { Püskürtme } \\
\text { basıc1 (bar) }\end{array}$ & $\begin{array}{c}\text { Örtme oran1 } \\
(\%)\end{array}$ & $\begin{array}{c}\text { Dövme Süresi } \\
(\mathrm{s})\end{array}$ & $\begin{array}{c}\text { Almen şiddeti } \\
(\mathrm{mmA})\end{array}$ \\
\hline \multirow{3}{*}{7.5} & \multirow{3}{*}{130} & $0,1-0,3(\mathrm{~S} 10)$ & 2 & 100 & 60 & 0,08 \\
\cline { 3 - 7 } & & $0,1-0,3(\mathrm{~S} 10)$ & 4 & 100 & 60 & 0,16 \\
\cline { 2 - 7 } & $0,4-0,9(\mathrm{~S} 60)$ & 2 & 100 & 60 & 0,32 \\
\cline { 2 - 6 } & & $0,4-0,9(\mathrm{~S} 60)$ & 4 & 100 & 60 & 0,70 \\
\hline
\end{tabular}

Bilyalı dövme deneyleri sonrasında yüzey altı özelliklerin incelenebilmesi için dövülen numunelerin hassas kesme cihazı ile kesitleri alınmış ve zımpara ve parlatma cihazı ile metalografik olarak hazırlanmıştır. Parlatılan numunelerin kesit mikroyapılarının görüntülenmesi için $2 \mathrm{ml}(\mathrm{HF}), 3 \mathrm{ml}(\mathrm{HCl}), 20 \mathrm{ml}\left(\mathrm{HNO}_{3}\right)$ ve $175 \mathrm{ml}\left(\mathrm{H}_{2} \mathrm{O}\right)$ kullanılarak hazırlanan dağlayıcı ile dağlanmıştır. Sertlik ölçümleri Shimadzu HMV-2 Vickers mikrosertlik cihazı kullanılarak gerçekleştirilmiştir. Bilyalı dövme işlemi öncesi ve sonrasında numunelerin mikrosertlik değerleri 100 gramlık yük 10 saniye süresince uygulanarak numune kesit yüzeyinden $30 \mu \mathrm{m}$ ' lik aralıklar ile yüzeyden merkeze doğru ölçülmüştür. Sertlik ölçümleri her bölge için 5 kez tekrarlanarak ölçülen sertlik değerlerinin ortalamaları alınmış ve mikrosertlik değerinin derinliğe bağlı olarak değişimi analiz edilmiştir. Farklı parametreler altında dövülen numunelerin yüzey altı mikroyapıları Carl Zeiss Axio Imager.A1m optik mikroskop ve Vega Tescan (II) taramalı elektron mikroskobu (SEM) yardımıyla incelenmiştir. 


\section{DENEYSEL SONUÇLAR VE TARTIŞMA (RESULTS \& DISCUSSION)}

\subsection{Yüzey altı sertliğin bilyalı dövme parametrelerine bağlı değişimi (The variation of the subsurface hardness depending on the shot peening parameters)}

Bu bölümde ilk olarak farklı parametreler altında bilyalı dövülen AA7075 T6 alüminyum alaşımının yüzey altı mikrosertlik değerlerinin derinliğe bağlı olarak değişimi tartışılacaktır. Brookmeier ve arkadaşları [40] bilyalı dövme esnasında yüzeye çarpan her bir bilyanın sahip olduğu kinetik enerji ile yüzeyde küçük ölçekli bir dövme gerçekleştirdiğini ve her bir bilyanın çarpması ile tekrarlanan bu dövme işleminin yüzeye yakın bölgelerde plastik deformasyona neden olduğunu açıklamışlardır. Bu sayede yüzeyde ve yüzeye yakın bölgelerde pekleşmeye bağlı olarak sertlik değerlerinin değişim gösterdiğini vurgulamışlardır [40]. Bu çalışmada bilyaların sahip oldukları kinetik enerjiler üzerinde etkinliği olan bilya püskürtme basıncı ve bilya boyutunun yüzey altında meydana gelen sertlik değerleri üzerindeki etkinliği tartış1lacaktır. Şekil 4' de 2 ve 4 bar püskürtme basınçlarında küçük $(0,1-0,3 \mathrm{~mm})$ ve büyük $(0,4-0,9 \mathrm{~mm})$ boyutlu paslanmaz çelik bilyalar ile dövülen alüminyum alaşımının sertliğinin derinliğe bağlı olarak değişimi verilmiştir.
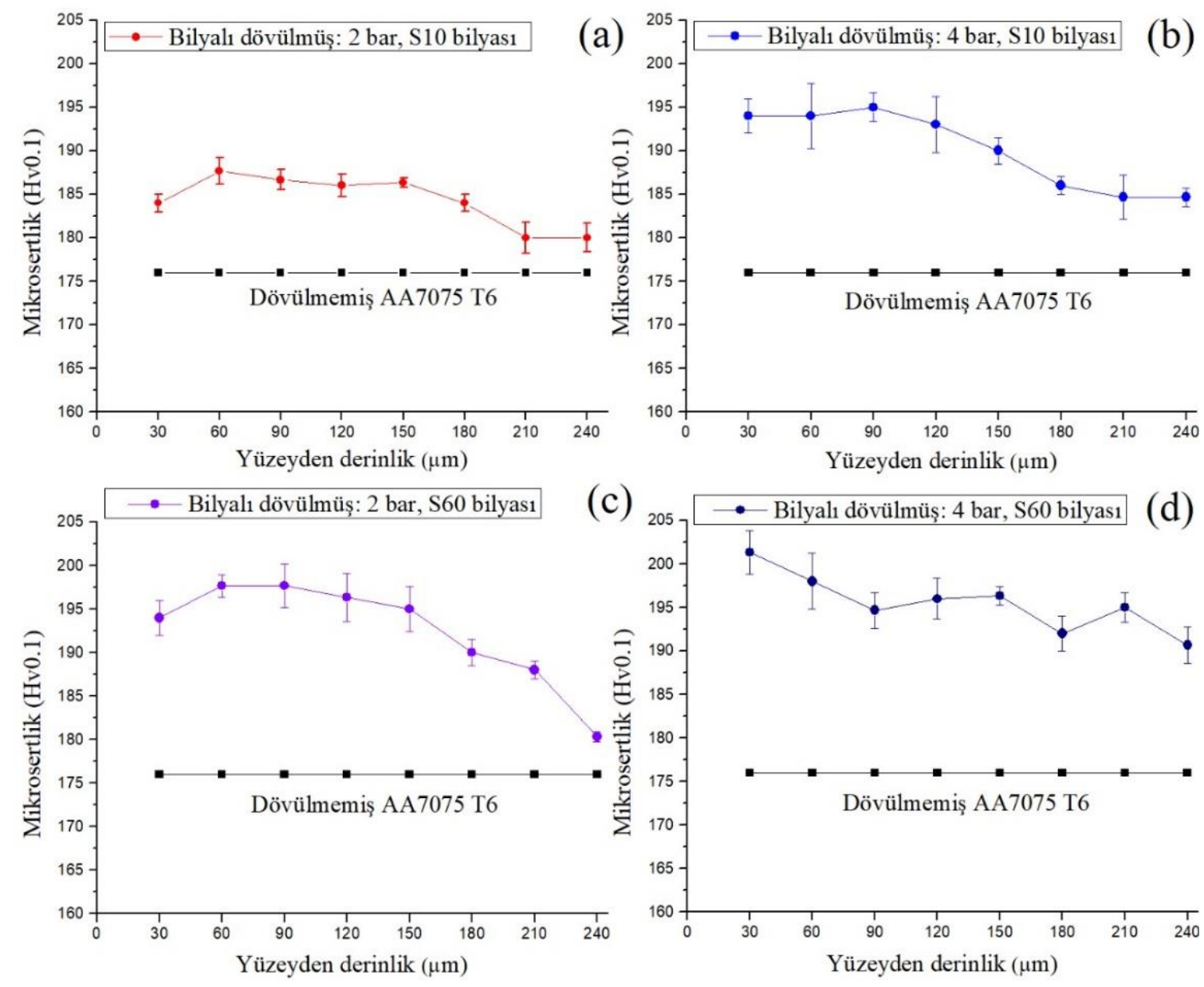

Şekil 4. Püskürtme basıncı ve bilya boyutuna bağlı olarak yüzey altı mikrosertlik değerinin değişimi (a) 2 bar ve $S 10(b) 4$ bar ve S10, (c) 2 bar $S 60$ (d) 4 bar ve $S 60$

Yüzey ve yüzey altı sertlik değerlerinin yaklaşık olarak 175 Hv0.1 olan işlem görmemiş alüminyum alaşımının farklı parametreler altında uygulanan bilyalı dövme işlemleri ile sertliğinin önemli miktarda artış gösterdiği Şekil 4' de verilen tüm grafiklerde net bir şekilde görülmektedir. Ancak sertlik artışının uygulanan parametreler bağlı olarak yüzeyden merkeze gidildikçe azaldığını ve belirli bir derinlikte etkinliğini önemli ölçüde yitirdiği görülmektedir. Mitrovic ve arkadaşları [2] bilyalı dövme uyguladıkları farklı alaşımlı çeliklerde özellikle yüzeye yakın bölgelerde belirgin bir sertlik artışı gözlemlemişler ve bu artışın yüzeyden merkeze doğru gidildikçe etkinliğinin azaldığını belirtmişlerdir. Ayrıca bilyalı dövme uygulanan malzemelerde sertlik artışının yüzeyde ve yüzey altı mikroyapısında meydana gelen tane 
küçülmesi ile meydana gelebileceğinin altını çizmişlerdir [2]. Okan Ünal ve Remzi Varol [17] düşük karbonlu çelik üzerine uyguladıkları bilyalı dövme işlemleri ile yüzeye yakın bölgelerde sertlik artışı gözlemlemişler ve bu artışın bu bölgelerde meydana gelen tane incelmesi ve yüksek dislokasyon artışına bağlamışlardır. Vielma ve arkadaşları [18] temperlenmiş orta karbonlu çeliklere uyguladıkları bilyalı dövme işlemi sonrası yüzeye yakın bölgelerde önemli bir sertlik artışı meydana geldiğini ve bu artışın merkeze doğru azaldığını belirtmişlerdir. Son olarak Zhang ve arkadaşları [41] alüminyum alaşımlarına uyguladıkları bilyalı dövme işlemleri sonrası benzer sonuçlara ulaşmışlardır. Bu noktada alüminyum alaşımının farklı parametreler altında bilyalı dövülmesi ile sertlik değerlerinde görülen arış eğiliminin (Şekil 4) literatürde genellikle çelikler üzerine gerçekleştirilen bilyalı dövme çalışmalarının sertlik ile ilgili sonuçları ile uyumlu olduğu söylenebilir.

Bilyalı dövme parametrelerinin yüzey altı sertlik değerlerine etkisi değerlendirildiğinde; püskürtme basıncının artışı ile elde edilen maksimum sertlik değerinin ve sertlik artışının etkin olduğu derinliğin bir miktar artış gösterdiği görülmektedir. Küçük boyutlu bilyalar ile dövülen numunelerde püskürtme basıncının arttırılması ile yüzey altı sertlik değerlerinin yaklaşık olarak 185 Hv0.1' den 195 Hv0.1' e yükseldiği görülmektedir (Şekil 4 (a) ve (b)). Diğer yandan büyük boyutlu bilyalar ile dövülen numunelerde basınç artışı ile yüzey altı sertlik değerlerinin 195 Hv0.1' den 200 Hv0.1' e yükseldiği söylenebilir (Şekil 4 (c) ve (d)). Bu sonuçlar ile basınç artışı ile birlikte sertlik artışının etkin olduğu derinliğinin önemli miktarda arttığı görülmektedir (Şekil 4). B. K.C. Ganesh ve arkadaşları [3] titanyum alaşımlarına farklı püskürtme basınçlarında bilyalı dövme uyguladıkları çalışmalarında Ti6A14V alaşımı için püskürtme basıncı artışı ile yüzey ve yüzeye yakın bölgelerde sertlik değerlerinin artış gösterdiğini ve sertlik artışı gözlenen bölgenin derinliğinin püskürtme basıncı ile doğru orantılı olarak arttığını sunmuşlardır. Ancak benzer sonuçları Ti6A17Nb alaşımı için gözlemleyememişlerdir [3]. H. Wang ve arkadaşları [42] A15052/Ti6A14V bindirme kaynak bölgesi üzerine uyguladıkları yüksek enerjili bilyalı dövme işleminde mikrosertlik değerlerinin derinliğe bağlı değişimlerini incelemişlerdir. Sertlik değerinin basınç artışı ile artış gösterdiğini göstermişlerdir. Bu artışın yüzey altında meydana gelen plastik deformasyon artışına ve tane küçülmesine bağlı olduğunu ve püskürtme basıncının azalması ile deformasyona uğrayan yüzey altı bölgenin derinliğinin azaldığını belirtmişlerdir [42]. Bu çalışmada incelenen AA7075 T6 alaşımının yüzey altı sertlik değerinin ve sertlik artışı gözlemlenen bölgenin derinliğindeki artışın literatürde bulunan farklı alüminyum ve titanyum alaşımlarına uygulanan çalışmalar ile uyumlu olduğu söylenebilir. S. Kikuchi ve arkadaşları [36] 5056 alüminyum alaşımına uyguladıkları bilyalı dövme çalışmasında sayısal modelleme ile bilyaların hızlarını analiz etmişler ve bilya hızlarının basınç ile orantılı olarak azalıp arttığı sonucunu sunmuşlardır [36]. Bu çalışmada gerçekleştirilen dövme işleminde püskürtme basıncı artışı ile bilyaların yüzeye çarpma hızlarının artış gösterdiği [36] ve buna bağlı olarak bilyaların yüzeye daha yüksek kinetik enerjiler ile daha fazla çarpma enerjisi ile dövme uyguladıkları söylenebilir. Sonuç olarak yüzey ve yüzey altı bölgenin basınç artışına bağlı olarak daha fazla plastik deformasyona uğradığı [42] ve plastik deformasyona uğrayan bölgenin derinliğinin artış gösterdiği [42] sonucuna varılabilir.

Her iki basınç değeri için bilya boyutunun yüzey altı sertliğe etkisi incelendiğinde bilya boyutunun artması ile sertlik değerinin önemli miktarda artış gösterdiği görülmektedir (Şekil 4). Bu artışa paralel olarak sertlik artışının etkin olduğu derinliğin de büyük boyutlu bilyaların kullanılması ile arttığı söylenebilir. Bu durumun bir sonucu olarak en yüksek sertlik değerleri 4 bar püskürtme basıncinda S60 (0,4-0,9 mm) paslanmaz çelik bilyalar ile gerçekleştirilen bilyalı dövme işlemi ile elde edildiği görülmektedir (Şekil 4 (d)). A. A. Ahmed ve arkadaşları [43] AISI 316L paslanmaz çeliğine uyguladıkları bilyalı dövme işlemleri sonucunda bilya boyutunun artışı ile yüzey altı mekanik özelliklerinde iyileşmeyi arttırdığını ve sertliği iyileşen yüzey tabakasının kalınlığının arttığı sonucuna varmışlardır [43]. Literatürde gerçekleştirilen çalışmalarda; bilya boyutunun artması ile yüzeyde meydana gelen plastik deformasyon artması [43] ve daha derin ve geniş çukurcuklar oluşumu [43] ile yüzey pürüzlülük değerlerinin artış gösterdiği görülmüştür [43, 44]. Bilya boyutu artışı ile daha yüksek gerinmelerin oluştuğu ve mikroyapıda daha etkin bir değişim meydana geldiği belirtilmiştir [45]. Bu bilgiler ışı̆̆ında bilya boyutu artışı ile AA7075 T6 alaşımının yüzey ve yüzeye yakın bölgelerinde meydana gelen plastik deformasyon miktarının artış gösterdiği söylenebilir. Bu değişimler ile birlikte yüzey altı mikroyapısında meydana gelen iyileşmenin de katkısı ile bilya boyutu artışı ile AA7075 T6 alaşımının yüzey altı sertlik değerlerinin iyileştiği ve iyileşme gözlenen bölgenin derinliğinin artış gösterdiği sonucuna varılmıştır. Yüzey altı sertliğinin iyileşmesine neden olan bu değişimler bir sonraki bölümde irdelenecektir. 


\subsection{Yüzey altı mikroyapısının bilyalı dövme parametrelerine bağlı değișimi (The variation of the subsurface microstructure depending on the shot peening parameters)}

Bu bölümde farklı parametreler altında bilyalı dövülen AA7075 T6 alüminyum alaşımının yüzey altı mikroyapısının derinliğe bağlı olarak değişimi tartışılacaktır. Şekil 5' de 2 bar ve 4 bar püskürtme basınçlarında $S 10(0,1-0,3 \mathrm{~mm})$ ve $S 60(0,4-0,9 \mathrm{~mm})$ bilyaları ile dövülen numunelerin optik mikroskop ile elde edilen mikroyapı fotoğrafları verilmiştir. Yüzey ve yüzey altında meydana gelen mikroyapısal değişimler bilyalı dövme sonucunda alüminyum alaşımında meydana gelen plastik deformasyonun kanıtı olarak gösterilebilir [46]. Özellikle büyük boyutlu bilyalar ile yüksek püskürtme basıncında dövülen numuneye ait mikroyapıda (Şekil 5(d)) yüzey ve yüzeye yakın bölgelerde meydana gelen aşırı plastik deformasyon ve bu deformasyona bağlı olarak yüzey formunun değişimi dikkat çekmektedir. Bilyalı dövme sonucunda yüzey ve yüzeye yakın bölgelerde görülen aşırı plastik deformasyon (Şekil 5) ile tane incelmesi ve dislokasyon yoğunluğunun artması bir önceki bölümde tartışılan sertlik artışının kök nedenleri olduğu söylenebilir [43]. A. Gariepy ve arkadaşları AA2024-T351 alüminyum alaşımına bilyalı dövme uyguladıkları çalışmalarında kesit mikroyapısında yüzeye yakın bölgelerde aşırı deformasyona uğramış tane yapısı belirlemişler ve bu yapının merkeze doğru gidildikçe ana malzeme yapısına dönüştüğünü göstermişlerdir [4]. Benzer sonuçların Şekil 5' de verilen mikroyapılar için geçerli olduğu söylenebilir. Diğer yandan bilyalı dövme ile yüzeyde çukurcukların oluştuğu görülmektedir [37]. Oluşan bu çukurcuklar mikroyapılarda beyaz oklar yardımı ile gösterilmiştir (Şekil 5). Bilyalı dövme ile aşırı plastik deformasyon ile yüzeyde derin çukurcukların oluşumu bilyalı dövme sonrası yüzey pürüzlüğünün önemli miktarda artmasına neden olabilmektedir $[8,47,48]$. Şekil 6-a' da verilen kesit SEM fotoğrafında bilyalı dövme ile yüzeyde meydana gelen plastik deformasyon sonucunda yüzeyde oluşan tahribat ve dalga formu görülmektedir. Şekil 6-b' de verilen yüzey morfolojisinde bilyalı dövme ile meydana gelen aşırı plastik deformasyon nedeniyle mikro çatlak oluşumu gözlenmektedir [47]. Şekil 7' de büyük boyutlu partiküller ile dövülen alüminyum alaşımının kesit mikroyapısında ve yüzey morfolojisinde de yoğun miktarda çatlak oluşumu gözlenmektedir. Literatürde benzer çatlakların bilyalı dövme sonucunda aşırı plastik deformasyon nedeniyle değişen yüzey pürüzlülüğüne bağlı olarak oluşabileceği belirtilmiştir [8]. Şekil 7 (b) de verilen yüzey morfolojisinde büyük boyutlu bilyaların yüksek çarpma enerjileri nedeniyle yüzeyde oluşturdukları derin ve geniş çukurlar görülmektedir.

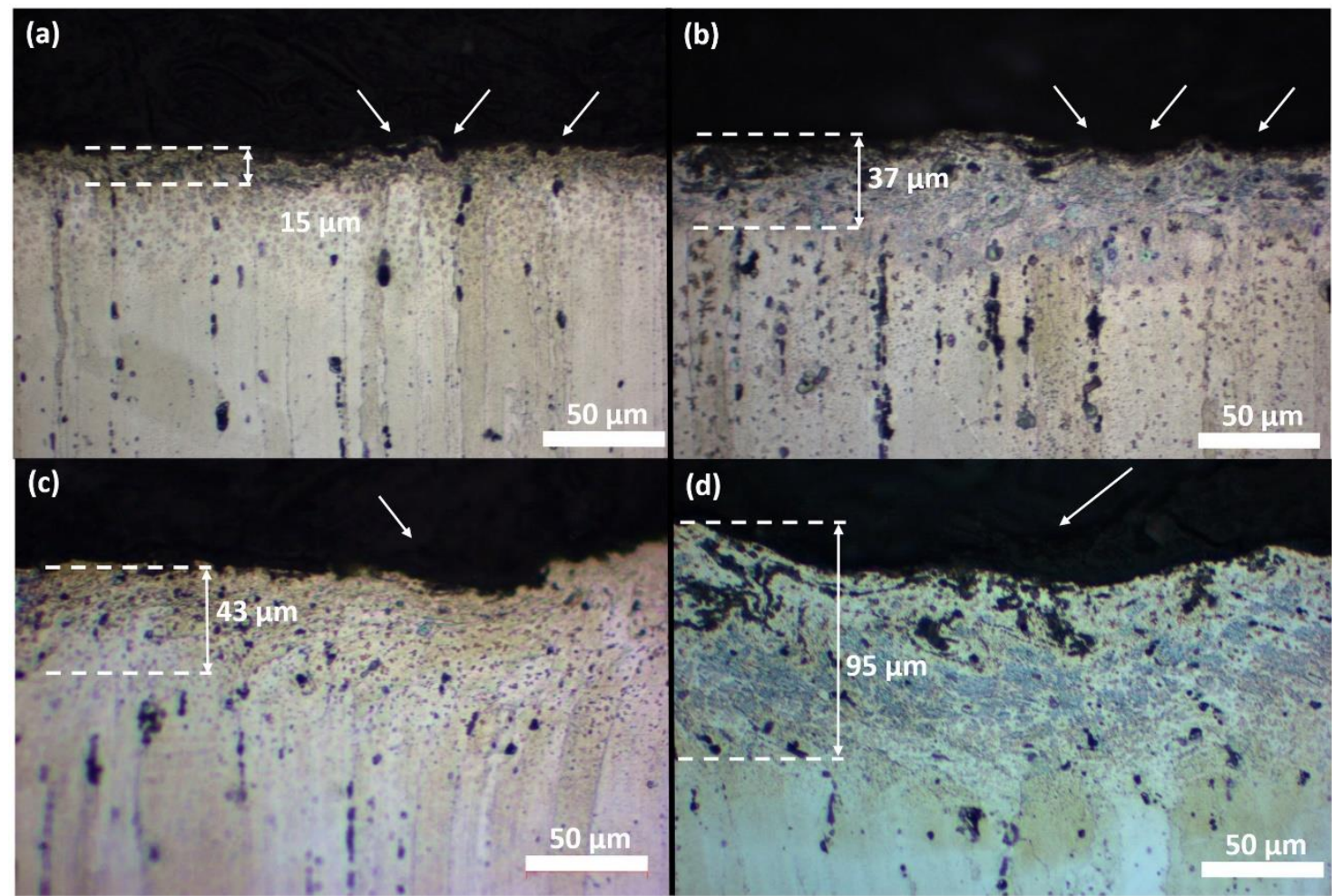

Şekil 5. Püskürtme basıncı ve bilya boyutuna bağlı olarak yüzey altı mikroyapısının değişimi (a) 2 bar ve S10 bilyası, (b) 4 bar ve S10 bilyası, (c) 2 bar S60 bilyası, (d) 4 bar ve S60 bilyası 
Şekil 5' de verilen mikroyapılarda yüzeye yakın bölgelerde aşırı plastik deformasyona uğramış bölgelerin kalınlıkları gösterilmiştir. Püskürtme basıncı artışı ile bu bölgelerin kalınlığının arttığı ve iç yapıda radikal değişikliklerin meydana geldiği görülmektedir (Şekil 5-b ve d). Püskürtme basıncının arttırılması ile dövme şiddetinin (Almen şiddeti) arttığı söylenebilir [3] (Tablo 3). Sonuç olarak aynı boyutlu bilyaların yüksek basınçta püskürtülmesi sonucunda artan dövme şiddeti ile birlikte plastik deformasyon miktarının ve değişime uğrayan iç yapının derinliğinin arttığ 1 Şekil 5'de net bir şekilde görülmektedir. Bu değişimler bir önceki bölümde tartışılan sertlik artışı ve sertlik artışı gösteren bölgenin derinliğinin püskürtme basıncı ile artışı sonuçlarını doğrulamaktadır (Şekil 4). Literatürde titanyum alaşımları için benzer sonuçları B. K. C. Ganesh ve arkadaşları sunmuşlardır [3]. Bunun ile birlikte artan püskürtme basıncına bağlı olarak Şekil 5' de oklar yardımı ile gösterilen yüzey çukurlarının derinliğinin ve boyutlarının arttı̆̆ı görülmektedir [36].
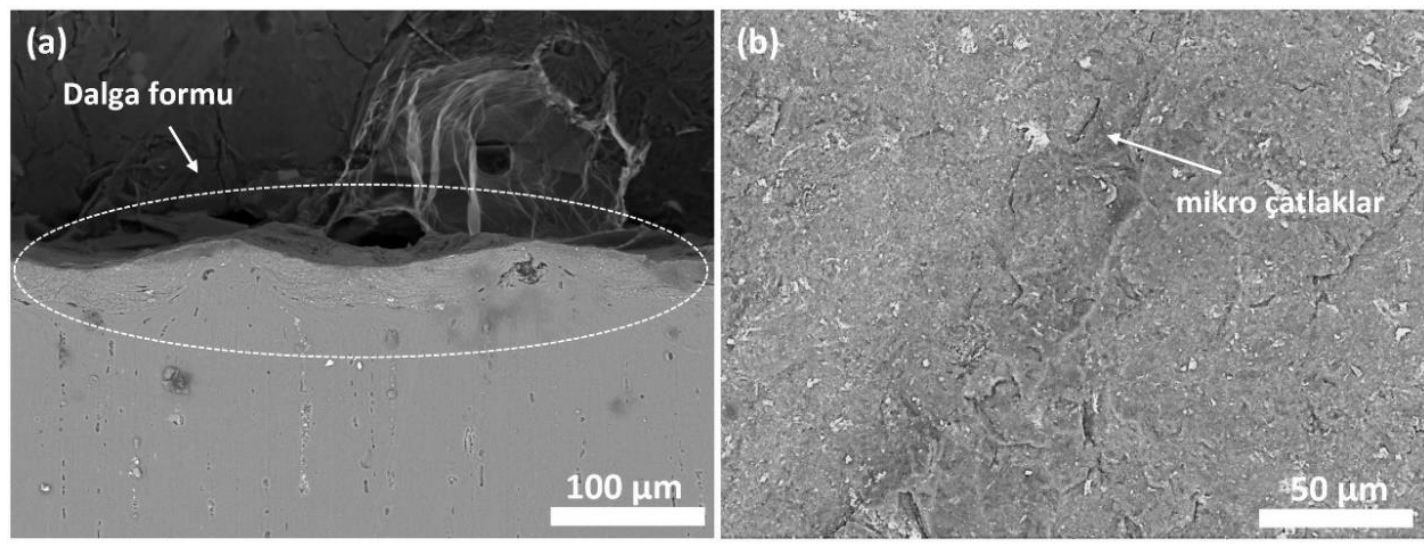

Şekil 6. S10 bilyası ile 4 bar basınçta dövülmüş̧ numunenin SEM fotoğrafları; (a) kesit mikroyapısl, (b) yüzey morfolojisi
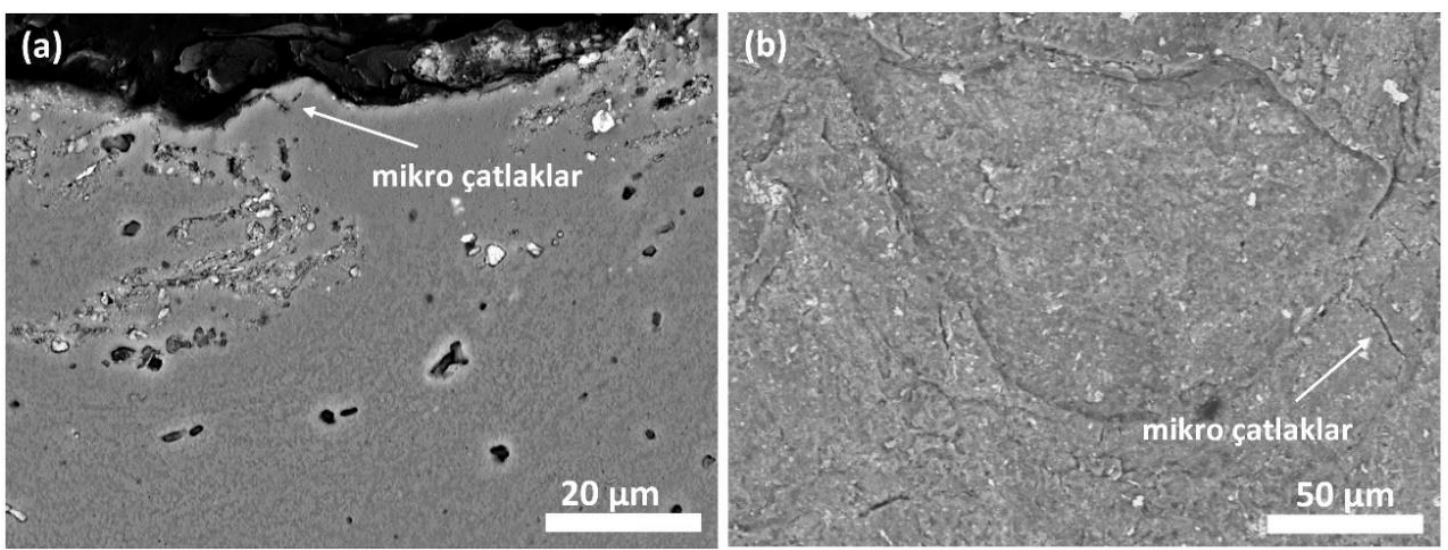

Şekil 7. S60 bilyası ile 2 bar basınçta dövülmüş numunenin SEM fotoğrafları; (a) kesit mikroyapısı, (b) yüzey morfolojisi

Bilya boyutunun yüzey altı mikroyapısına etkileri irdelendiğinde, artan bilya boyutu ile her iki basınç değerinde de mikroyapıda meydana gelen değișimin şiddetinin ve deformasyona bağlı değișim gösteren bölgenin derinliğinin arttığı söylenebilir (Şekil 5). Așırı deformasyona uğrayan bölge derinliğinin bilya boyutu artışı ile 2 katın üzerinde artış gösterdiği dikkat çekmektedir. Literatürde bilya boyutunun mekanik özelliklerin artışı üzerinde etkili olduğu ve değişim gösteren yüzey altı bölgenin derinliğini etkilediği belirtilmiştir [41]. Ancak büyük boyutlu bilyaların yüzeyde aşırı plastik deformasyona yol açabileceği uyarısında bulunulmuștur [41]. Büyük boyutlu bilyalar ile dövülen numunelerin optik mikroskop (Şekil 5(c) ve (d)) ve SEM (Şekil 7(a)) fotoğraflarında yüzeyde meydana gelen aşırı deformasyon görülmektedir. Bilya boyutu artışına bağlı olarak mikroyapıda oluşan plastik gerinmelerin artış gösterdiği ve bu durumun mikroyapısal değişimleri hızlandırdığı belirtilmiştir [45]. Malzemede oluşan gerinmelerin bilyaların hızına ve kütlesine bağlı olarak değişen kinetik enerjilerine bağlı olduğu sonucu vurgulanmıştır [45]. Literatürde farklı malzemelere uygulanan dövme işlemleri ile ilgili öne sürülen bu sonuçlar, AA7075 T6 alaşımının büyük boyutlu bilyalar ile dövülmesi durumunda küçük boyutlu bilyalar ile dövülen numunelere göre mikroyapısında daha fazla değişim gözlenmesini, daha yüksek sertlik değerlerinin elde edilmesini ve sertlik artışı gösteren bölgenin derinliğinin artışını doğrular niteliktedir. 


\section{SONUÇ (CONCLUSION)}

Bu çalışmada bilyalı dövme işleminde püskürtme basıncı ve bilya boyutu parametrelerinin AA7075 T6 alaşımının yüzey altı mekanik ve mikroyapısal özelliklerine etkileri incelenmiştir. Çalışmanın sonuçları aşağıda özetlenmiştir.

i) AA7075 T6 alaşımının bilyalı dövme işlemi için püskürtme basıncı ve bilya boyutu parametrelerinin alaşımının yüzey altı sertliği ve mikroyapısı üzerinde önemli bir etkisi olduğu sonucuna varılmıştır.

ii) Püskürtme basıncı ve bilya boyutu artışı alaşımın yüzey altı sertlik değerlerinde artışa neden olmuştur. Bunun ile birlikte bilyalı dövme işleminin daha büyük bilyalarla daha yüksek püskürtme basınçlarında gerçekleştirilmesi sonucunda yüzey altı sertliğinin ve deforme olmuş yüzey altı bölgenin derinliğinin önemli miktarda arttığ belirlenmiştir. Bu durum artan püskürtme basıncı ve bilya boyutu ile bilyaların sahip olduğu kinetik enerji artışı sonucunda daha şiddetli bir dövme işlemi gerçekleştirilmesi ile ilişkilendirilmiştir.

iii) Bilyalı dövme işlemi ile değişen yüzey altı mikroyapısı optik mikroskop ve taramalı elektron mikroskobu çalışmaları ile net bir şekilde ortaya konulmuştur. Artan basınç ve bilya boyutu mikroyapıda meydana gelen değişimin şiddetini ve derinliğini arttırmıştır.

iv) Yüksek püskürtme basıncında özellikle büyük boyutlu bilyalar ile gerçekleştirilen bilyalı dövme işlemleri sonrasında yüzey altı bölgede aşırı plastik deformasyonlar meydana geldiği görülmüştür. Bu bölgenin derinliğinin basınç ve boyut artışı ile orantılı olarak arttığı gözlenmiştir. Aşırı plastik deformasyon nedeniyle; yüzey morfolojisinde aşırı deformasyon meydana geldiği, yüzeyde dalga formu şeklinde hasar oluştuğu, derin ve geniş çukurcukların oluştuğu ve yüzeysel mikro çatlakların meydana geldiği sonucuna varılmıştır.

Yukarıda özetlenen sonuçların bilimsel ve endüstriyel çalışmalarda bilyalı dövülen başta alüminyum alaşımları olmak üzere metal alaşımlarının yüzey altı mekanik ve mikroyapısal özelliklerinin istenildiği gibi kontrol edilebilmesi ve bu özelliklerin bilya boyutu ve püskürtme basıncı parametrelerine bağlı olarak değişiminin kök nedenlerinin anlaşılması noktasında fayda sağlayacağı düşünülmektedir. Çalışmanın daha da derinleştirilmesi ve kapsamının arttırılması için transmisyon elektron mikroskobu, nano indentasyon ve kalıntı gerilme analizi gibi yeni karakterizasyon yöntemleri ile çalışmada incelenen parametrelerin yanında bilya türü, tekrar sayısı, bilya açısı gibi diğer bilyalı dövme işlem parametrelerinin kullanıldığı yeni çalışmaların gerçekleştirilmesi planlanmaktadır.

Son olarak giriş bölümünde yer alan literatür çalışmalarında da belirtildiği gibi alüminyum alaşımlarının yorulma davranışlarının bilyalı dövme ile geliştirilmesi üzerine çok sayıda çalışma gerçekleştirilmiş ve bu çalışmaların büyük bir kısmında bilyalı dövme işlem parametrelerinin alüminyum alaşımlarının yorulma ömrüne etkileri üzerine odaklanılmıştır. Ancak bilyalı dövme ile yorulma davranışının değişimine neden olan yüzey ve yüzey altı mekanik özelliklere ve mikroyapısal değişimlere bilyalı dövme parametrelerinin etkileri üzerine sınırlı sayıda sonuç sunulmuştur. Bu çalışmada sunulan sonuçlar, alüminyum alaşımlarının farklı parametreler altında bilyalı dövme ile yorulma dayanımının geliştirilmesi üzerine gerçekleştirilecek çalışmalar için yorulma davranışını etkileyen yüzey ve yüzey altı mekanik ve mikroyapısal özelliklerin bilyalı dövme parametrelerine bağlı olarak değişimlerinin anlaşılması konusunda bir kaynak oluşturması beklenmektedir.

\section{TEŞEKKÜR (ACKNOWLEDGEMENTS)}

Sakarya Üniversitesi, Mühendislik Fakültesi, Metalurji ve Malzeme Mühendisliği Bölümü, Termal Sprey Arş. ve Uygulama Laboratuvarı Yöneticisi Prof. Dr. Fatih Üstel'e ve Laboratuvar Koordinatörü Arş. Gör. Dr. Fatih Erdem Baştan'a mikroyapı ve mikrosertlik incelemelerindeki katkılarında dolayı teşekkür ederim. Deneysel ve yazım çalışmalarının genelinde yardımlarını esirgemeyen Kocaeli Üniversitesi, Makine Müh. Bölümü Yüksek Lisans öğrencisi Okan Yetik’e, Manchester Üniversitesi, Malzeme Müh. Bölümü Doktora öğrencisi Berzah Yavuzyeğit'e ve Kocaeli Üniversitesi, Makine Müh. Böl. Arş. Gör. Yasemin Yıldıran Avcu' ya teşekkürlerimi sunarım. 


\section{KAYNAKLAR (REFERENCES)}

[1] M. Mhaede, Influence of surface treatments on surface layer properties, fatigue and corrosion fatigue performance of AA7075 T73. Materials \& Design, 41 (2012) 61-66.

[2] S. Mitrovic, D. Adamovic, F. Zivic, D. Dzunic, M. Pantic, Friction and wear behavior of shot peened surfaces of 36CrNiMo4 and 36NiCrMo16 alloyed steels under dry and lubricated contact conditions. Applied Surface Science, 290 (2014) 223-232.

[3] B.K.C. Ganesh, W. Sha, N. Ramanaiah, A. Krishnaiah, Effect of shotpeening on sliding wear and tensile behavior of titanium implant alloys. Materials \& Design, 56 (2014) 480-486.

[4] A. Gariépy, F. Bridier, M. Hoseini, P. Bocher, C. Perron, M. Lévesque, Experimental and numerical investigation of material heterogeneity in shot peened aluminium alloy AA2024-T351. Surface and Coatings Technology, 219 (2013) 15-30.

[5] S. Žagar, J. Grum, Surface Modification Analysis after Shot Peening of AA 7075 in Different States. Materials Science Forum, $768-769$ (2013) 519-525.

[6] M. Benedetti, V. Fontanari, M. Bandini, E. Savio, High- and very high-cycle plain fatigue resistance of shot peened high-strength aluminum alloys: The role of surface morphology. International Journal of Fatigue, 70 (2015) 451-462.

[7] A. Gariépy, S. Larose, C. Perron, P. Bocher, M. Lévesque, On the effect of the orientation of sheet rolling direction in shot peen forming. Journal of Materials Processing Technology, 213:6 (2013) 926-938.

[8] L. Trško, O. Bokůvka, F. Nový, M. Guagliano, Effect of severe shot peening on ultra-high-cycle fatigue of a low-alloy steel. Materials \& Design, 57 (2014) 103-113.

[9] Y. Sun, Sliding wear behaviour of surface mechanical attrition treated AISI 304 stainless steel. Tribology International, 57 (2013) 67-75.

[10] M.K. Kulekci, U. Esme, Critical analysis of processes and apparatus for industrial surface peening technologies. The International Journal of Advanced Manufacturing Technology, 74: 9-12 (2014) 15511565 .

[11] C.W. Ziemian, M.M. Sharma, B.D. Bouffard, T. Nissley, T.J. Eden, Effect of substrate surface roughening and cold spray coating on the fatigue life of AA2024 specimens. Materials \& Design, 54 (2014) 212-221.

[12] X.-f. Sheng, Q.-x. Xia, X.-q. Cheng, L.-s. Lin, Residual stress field induced by shot peening based on random-shots for 7075 aluminum alloy. Transactions of Nonferrous Metals Society of China, 22 (2012) s261-s267.

[13] L. Xie, C. Jiang, W. Lu, The influence of shot peening on the surface properties of (TiB+TiC)/Ti6Al-4V. Applied Surface Science, 280 (2013) 981-988.

[14] L. Trško, M. Guagliano, O. Bokůvka, F. Nový, Fatigue life of AW 7075 Aluminium Alloy after Severe Shot Peening Treatment with Different Intensities. Procedia Engineering, 74 (2014) 246-252.

[15] M. Ahmadi, B.M. Sadeghi, M. Irani, F. Rahimi, Finite element simulation of shot peening of an aluminum alloy considering hardening models. Russian Journal of Non-Ferrous Metals, 57: 6 (2017) 565571.

[16] V.B. Nguyen, H.J. Poh, Y.-W. Zhang, Predicting shot peening coverage using multiphase computational fluid dynamics simulations. Powder Technology, 256 (2014) 100-112. 
[17] O. Unal, R. Varol, Almen intensity effect on microstructure and mechanical properties of low carbon steel subjected to severe shot peening. Applied Surface Science, 290 (2014) 40-47.

[18] A.T. Vielma, V. Llaneza, F.J. Belzunce, Effect of coverage and double peening treatments on the fatigue life of a quenched and tempered structural steel. Surface and Coatings Technology, 249 (2014) 7583.

[19] J. González, S. Bagherifard, M. Guagliano, I. Fernández Pariente, Influence of different shot peening treatments on surface state and fatigue behaviour of Al 6063 alloy. Engineering Fracture Mechanics, 185 (2017) 72-81.

[20] D. Cecchin, C.L. Azanza Ricardo, M. D'Incau, M. Bandini, P. Scardi, Influence of Shot-Peening Parameters on the Sub-Surface Residual Stress Profiles in Al-7075 Alloy Components. Materials Science Forum, 768-769 (2013) 66-71.

[21] M. Marini, V. Fontanari, M. Bandini, M. Benedetti, Surface layer modifications of micro-shot-peened Al-7075-T651: Experiments and stochastic numerical simulations. Surface and Coatings Technology, 321 (2017) 265-278.

[22] L. Trško, M. Guagliano, O. Bokůvka, F. Nový, M. Jambor, Z. Florková, Influence of Severe Shot Peening on the Surface State and Ultra-High-Cycle Fatigue Behavior of an AW 7075 Aluminum Alloy. Journal of Materials Engineering and Performance, 26:6 (2017) 2784-2797.

[23] L. Xie, L. Wang, C. Jiang, W. Lu, The variations of microstructures and hardness of titanium matrix composite (TiB+TiC)/Ti-6Al-4V after shot peening. Surface and Coatings Technology, 244 (2014) 69-77.

[24] J. Milligan, M. Brochu, Cladding AA7075 with a cryomilled Al-12Si alloy using spark plasma sintering. Materials Science and Engineering: A, 578 (2013) 323-330.

[25] Y.C. Lin, Y.-Q. Jiang, X.-M. Chen, D.-X. Wen, H.-M. Zhou, Effect of creep-aging on precipitates of 7075 aluminum alloy. Materials Science and Engineering: A, 588 (2013) 347-356.

[26] U.M.R. Paturi, S.K.R. Narala, R.S. Pundir, Constitutive flow stress formulation, model validation and FE cutting simulation for AA7075-T6 aluminum alloy. Materials Science and Engineering: A, 605 (2014) 176-185.

[27] Y. Jin, P. Cai, W. Wen, H. Nagaumi, B. Xu, Y. Zhang, T. Zhai, The anisotropy of fatigue crack nucleation in an AA7075 T651 Al alloy plate. Materials Science and Engineering: A, 622 (2015) 7-15.

[28] B. Hu, I.M. Richardson, Microstructure and mechanical properties of AA7075(T6) hybrid laser/GMA welds. Materials Science and Engineering: A, 459:1-2 (2007) 94-100.

[29] B. Mishra, C. Mondal, R. Goyal, P. Ghosal, K.S. Kumar, V. Madhu, Plastic flow behavior of 7017 and 7055 aluminum alloys under different high strain rate test methods. Materials Science and Engineering: A, 612 (2014) 343-353.

[30] W. Huo, L. Hou, H. Cui, L. Zhuang, J. Zhang, Fine-grained AA 7075 processed by different thermomechanical processings. Materials Science and Engineering: A, 618 (2014) 244-253.

[31] M. Taheri-Mandarjani, A. Zarei-Hanzaki, H.R. Abedi, Hot ductility behavior of an extruded 7075 aluminum alloy. Materials Science and Engineering: A, 637 (2015) 107-122.

[32] M. Bahrami, M. Farahmand Nikoo, M.K. Besharati Givi, Microstructural and mechanical behaviors of nano-SiC-reinforced AA7075-O FSW joints prepared through two passes. Materials Science and Engineering: A, 626 (2015) 220-228. 
[33] S. Bayazid, H. Farhangi, H. Asgharzadeh, L. Radan, A. Ghahramani, A. Mirhaji, Effect of cyclic solution treatment on microstructure and mechanical properties of friction stir welded $7075 \mathrm{Al}$ alloy. Materials Science and Engineering: A, 649 (2016) 293-300.

[34] E. Avcu, The influences of ECAP on the dry sliding wear behaviour of AA7075 aluminium alloy. Tribology International, 110 (2017) 173-184.

[35] K.T. Cho, K. Song, S.H. Oh, Y.-K. Lee, K.M. Lim, W.B. Lee, Surface hardening of aluminum alloy by shot peening treatment with Zn based ball. Materials Science and Engineering: A, 543 (2012) 44-49.

[36] S. Kikuchi, Y. Nakamura, K. Nambu, M. Ando, Effect of shot peening using ultra-fine particles on fatigue properties of 5056 aluminum alloy under rotating bending. Materials Science and Engineering: A, 652 (2016) 279-286.

[37] Y.-S. Nam, Y.-I. Jeong, B.-C. Shin, J.-H. Byun, Enhancing surface layer properties of an aircraft aluminum alloy by shot peening using response surface methodology. Materials \& Design, 83 (2015) 566576.

[38] K. Oguri, Fatigue life enhancement of aluminum alloy for aircraft by Fine Particle Shot Peening (FPSP). Journal of Materials Processing Technology, 211: 8 (2011) 1395-1399.

[39] U. Zupanc, J. Grum, Surface Integrity of Shot Peened Aluminium Alloy 7075-T651. Strojniški vestnik - Journal of Mechanical Engineering, 57: 05 (2011) 379-384.

[40] H.-G. Brokmeier, M.C. Avalos, R.E. Bolmaro, E. Maawad, Surface Microstructure Modification in Square Extruded Al-Nb Powder Composites by Shot Peening. IOP Conference Series: Materials Science and Engineering, 63 (2014) 012015.

[41] X. Zhang, K. Liao, V. Ji, H. Chen, L. Hu, Effect of the shot peening on the deformation of Al alloy component. Surface Engineering, DOI 10.1080/02670844.2017.1380359 (2017) 1-8.

[42] H. Wang, X. Yuan, K. Wu, C. Xu, Y. Jiao, W. Ge, J. Luo, Effect of high energy shot-peening on the microstructure and mechanical properties of Al5052/Ti6Al4V lap joints. Journal of Materials Processing Technology, 255 (2018) 76-85.

[43] A.A. Ahmed, M. Mhaede, M. Basha, M. Wollmann, L. Wagner, The effect of shot peening parameters and hydroxyapatite coating on surface properties and corrosion behavior of medical grade AISI 316L stainless steel. Surface and Coatings Technology, 280 (2015) 347-358.

[44] E. Avcu, Surface properties of AA7075 aluminium alloy shot peened under different peening parameters. Acta Materialia Turcica, 1 (2017) 3-10.

[45] S.V. Komarov, S.E. Romankov, Mechanical metallization of alumina substrate through shot impact treatment. Journal of the European Ceramic Society, 34: 2 (2014) 391-399.

[46] M. Abdulstaar, M. Mhaede, M. Wollmann, L. Wagner, Investigating the effects of bulk and surface severe plastic deformation on the fatigue, corrosion behaviour and corrosion fatigue of AA5083. Surface and Coatings Technology, 254 (2014) 244-251.

[47] J. Vázquez, C. Navarro, J. Domínguez, Experimental results in fretting fatigue with shot and laser peened Al 7075-T651 specimens. International Journal of Fatigue, 40 (2012) 143-153.

[48] C. Rodopoulos, Optimisation of the fatigue resistance of 2024-T351 aluminium alloys by controlled shot peening - methodology, results and analysis. International Journal of Fatigue, $26: 8$ (2004) 849-856. 